\title{
THE ADVANTAGES OF INTELIGENT APPROACH TO MACHINING PRESENTED THROUGH PROCESSING TECHNOLOGY DESIGN DEVELOPED BY I-MACHINING
}

\author{
Goran Duduković* \\ Solfins DOO, Belgrade, Serbia \\ Milutin Ogrizović \\ Technical school, Stara Pazova, Serbia
}

The modern day efficient machining requires a new approach to designing machining technology, which enables the complete engagement of all technological machining parameters, like cutting speed and cutting feed depending on the work piece material, characteristics of the machine and tools and volume of the material removed from the machined zone. Controlling physical quantities, which appear in the process of cutting, enables us to achieve faster machining processes when compared to current high speed machining technologies (HSM) and at the same it increases productivity. This approach to machining requires the CAM software intelligence to make decisions in real time and optimize tool path, in order to keeping the constant cutting tool force during whole machining process. This type of approach was used while designing machining for "heat exchanger"with the help of imachiningtechnology within SolidCAMsoftware for programing of CNC machines. Where by reduced the machining time for $36 \%$ in accordance to conventional machining and made a total savings of $45.33 \%$.

Key words: Side step, Constant cutting force, Efficient machining, I-machining technology

\section{INTRODUCTION}

Imachining technology represents an implemented set of experiences and data in SolidCAM software for designing of machining technology, on which the basic algorithm for creating of optimum tool path is based, Figure 1.

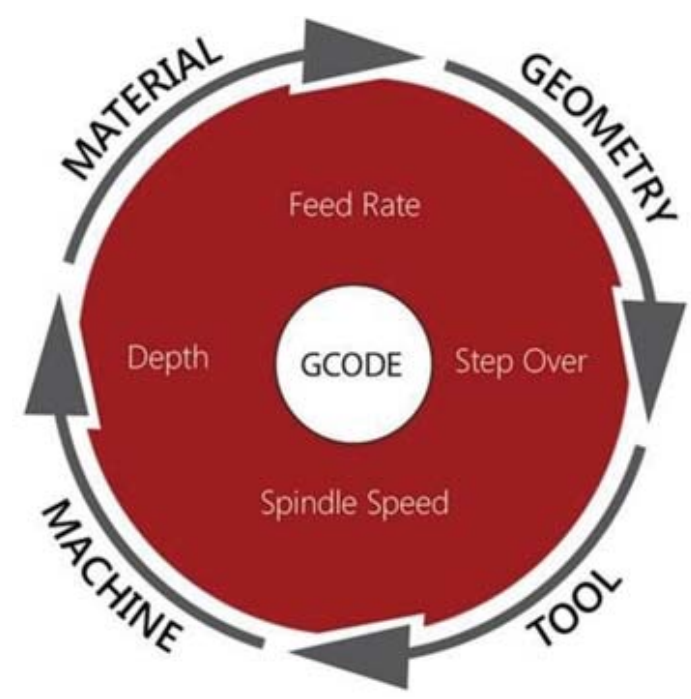

Figure 1: Interactive parameter strategy of imachining technology
Based on the integrated information about tool, workpiece material and geometry and machine capability, imachining technology automatically synchronizes the cutting speed, cutting feed, cutting depth, milling width, chip thickness and chip shape while creating the executiveg codefile for programing of CNC machine.

Synchronizing the cutting conditions is present during the total tool path depending of the tool involvement degree, i.e.Side step value, Figure 2.
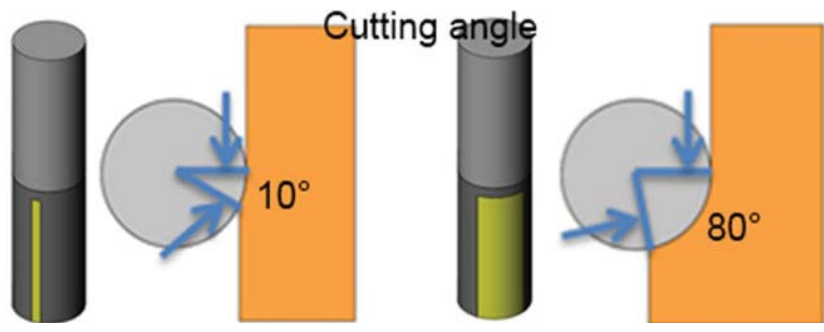

Figure 2: Example of tool engagement degree through active Side step

In this way we can create perfectly smooth and tangential tool path, which avoid the overuse of the tool and eliminate air cutting, implicating productivity increase and tool wear reduction, Figure 3. 

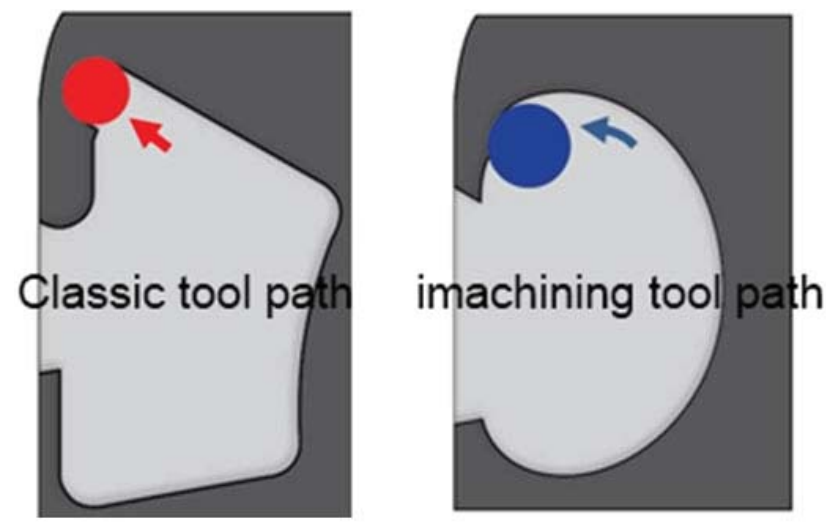

Figure 3: Example of the classic tool path (left) and imachining tool path (right)

\section{DESIGNING MACHINING WITH IMACHINING TECHNOLOGY}

\section{Imachining technology advantages}

The research of current designing machining methodology has shown that there is an incomplete and inadequate control of tool path leading to tool overuse and a large number of air cutting in most cases. That is the reason for the development of advanced generation of designing machining for fast material removal with built -in intelligence, the so called imachining technology which enables the completely automatic tool path control and cuttingconditions based on the machining parameters. The user does not have to have a wide technological knowledge, because it has already been integrated in the technological base it self. It is just necessary to choose the machine andappropriate tool based on workpiece material. Namely, the integrated

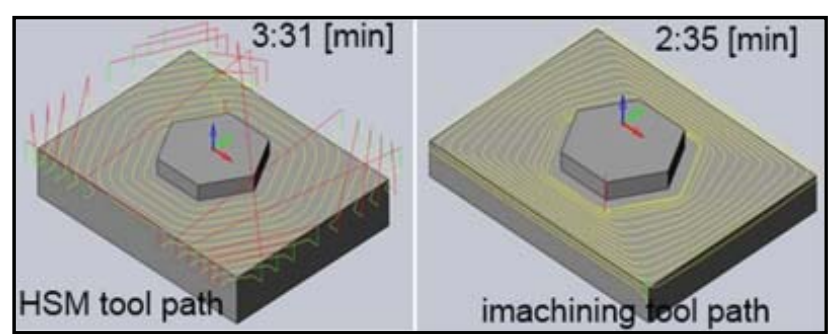

Figure 4: Comparable display of tool path HSM and imachining technology

algorithm is capable of making decisions in real time during machining and providing multi-criteria optimization:

\section{Geometric tool path optimization}

Comparable display of tool path for end milling cutter $\emptyset \varnothing 10[\mathrm{~mm}]$ obtained by HSM technology on the left, andimachining technology on the right clearly shows the elimination of air cutting and tool overuse, the tool path obtained through imachining technology is clearly visible and adapted to part geometry with changeable Side step, i.e. milling width, Figure 4 . The cutting depth is increased from 0.313 [mm] to 3.14 [mm]. Machining time in the first case took 3:31 [min], whileimachining technology reduced the machining time to $2: 35$ [min], by $28 \%$.

\section{Cutting condition optimization}

Software automatically calculates the values of cutting speed and cutting feed for the projectedtool path, because their values oscillate in every tool path point depending on the Side step. These calculations are necessary for achievement of constant value of cutting force, Figure 5.
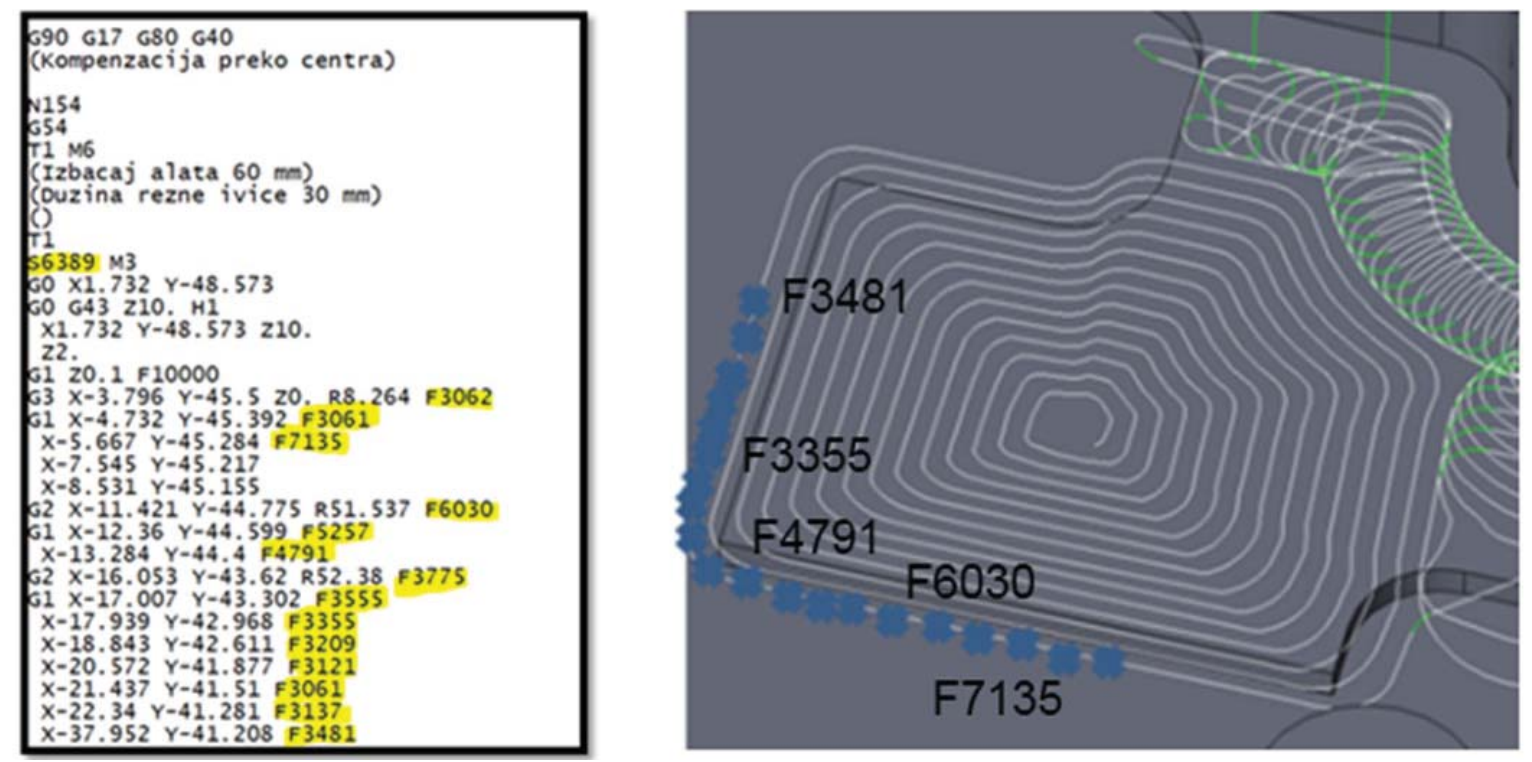

Figure 5: Executive G code file and several points on the tool path with different cutting feed 


\section{Imachining technology disadvantages}

In order forimachining technology to work properly, we have to input empirical data in the technological base kept in two tables connected with appropriate relations based on which the algorithm optimizes the tool path. It is necessary to define machine characteristics, like the power of engine drive, efficiency, the max spindle speed and max Side step. The current data on material require only the value of Ultimate tensile material strength Rm[MPa], Figure 6.

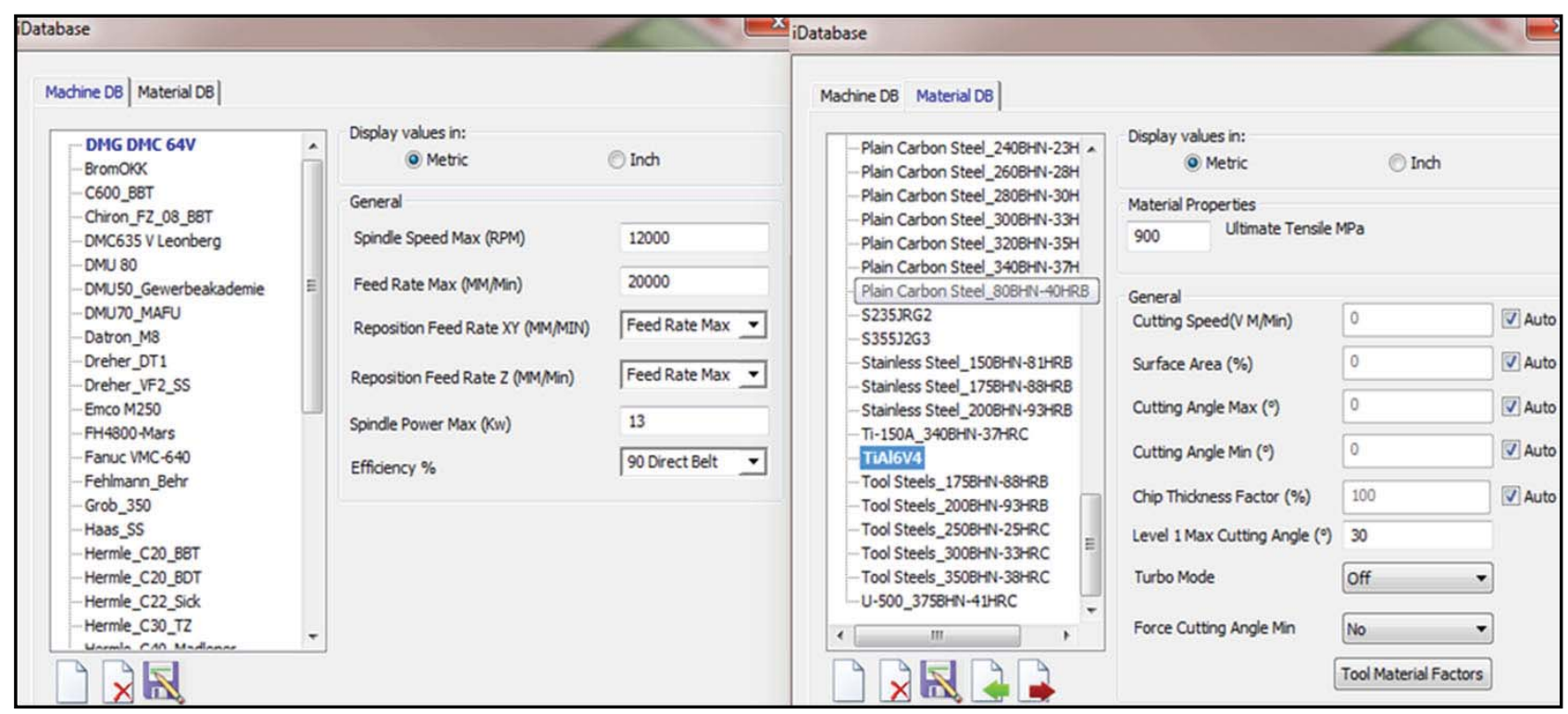

Figure 6: Technological base of selected machine and materials

Current algorithm does not take into consideration other machinability parameters, but the user could manually modify other values as necessary in technological material base. The earlier versions used as basic machining parameter the value of unit power necessary to remove $1 \mathrm{~cm}^{3}$ material. Because of the complexity of calculating the value of this parameter, today's program package version was upgraded and requires the input of Ultimate tensile material strength which is easily found on the material properties site: www.matweb.com.

\section{PROPERTIES OF MACHINE, TOOLS AND WORKPIECE MATERIAL}

The example material we used was titanium alloy Ti6Al4V, with the following properties, Table 1.

Table 1: Mechanical properties of titanium alloy Ti6Al4V

\begin{tabular}{|c|c|c|c|}
\hline \multicolumn{4}{|l|}{ MECHANICAL PROPERTIES } \\
\hline & Arcam Ti6Al4V & Ti6AI4V, Required** & Ti6AI4V, Required ${ }^{* *}$ \\
\hline Yield Strength $\left(R_{p} 0.2\right)$ & $950 \mathrm{MPa}$ & $758 \mathrm{MPa}$ & $860 \mathrm{MPa}$ \\
\hline Ultimate Tensile Strength $\left(R_{m}\right)$ & $1020 \mathrm{MPa}$ & $860 \mathrm{MPa}$ & $930 \mathrm{MPa}$ \\
\hline Elongation & $14 \%$ & $>8 \%$ & $>10 \%$ \\
\hline Reduction of Area & $40 \%$ & $>14 \%$ & $>25 \%$ \\
\hline Fatigue Strength* @ $600 \mathrm{MPa}$ & $>10,000,00$ cycles & & \\
\hline Rockwell Hardness & $33 \mathrm{HRC}$ & & \\
\hline Modulus of Elasticity & $120 \mathrm{GPa}$ & & \\
\hline
\end{tabular}

Due to extreme toughness and Ultimate tensile material strength this alloy represents one of the most difficult machining materials. These alloy properties: high strength, corrosion resistance and low specific mass $4430\left[\mathrm{~kg} / \mathrm{m}^{3}\right]$, have influenced its application in special branches of industry: military, medicine and air, despite its cost. One of the examples is the heat exchanger (Product ID: 681200.12) for which designed machining technology was created. 
The said heat exchanger has, among other uses, application in military industry, Figure 7.

During machining we used End Mill tool manufactured by SECO Tools JABRO SOLID series of universal tool. We used tool diameter $\varnothing 10[\mathrm{~mm}]$, number of flutes $4, \varnothing 6[\mathrm{~mm}]$, number of flutes 4 , Figure 8.

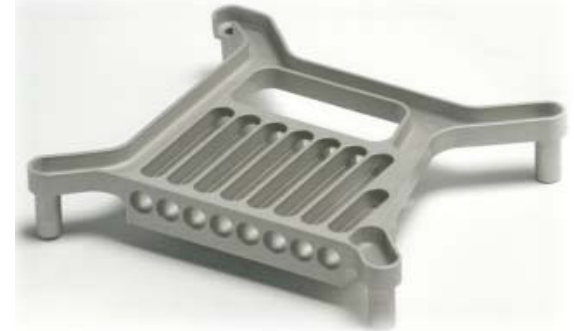

Figure 7: Heat exchanger-681200.12

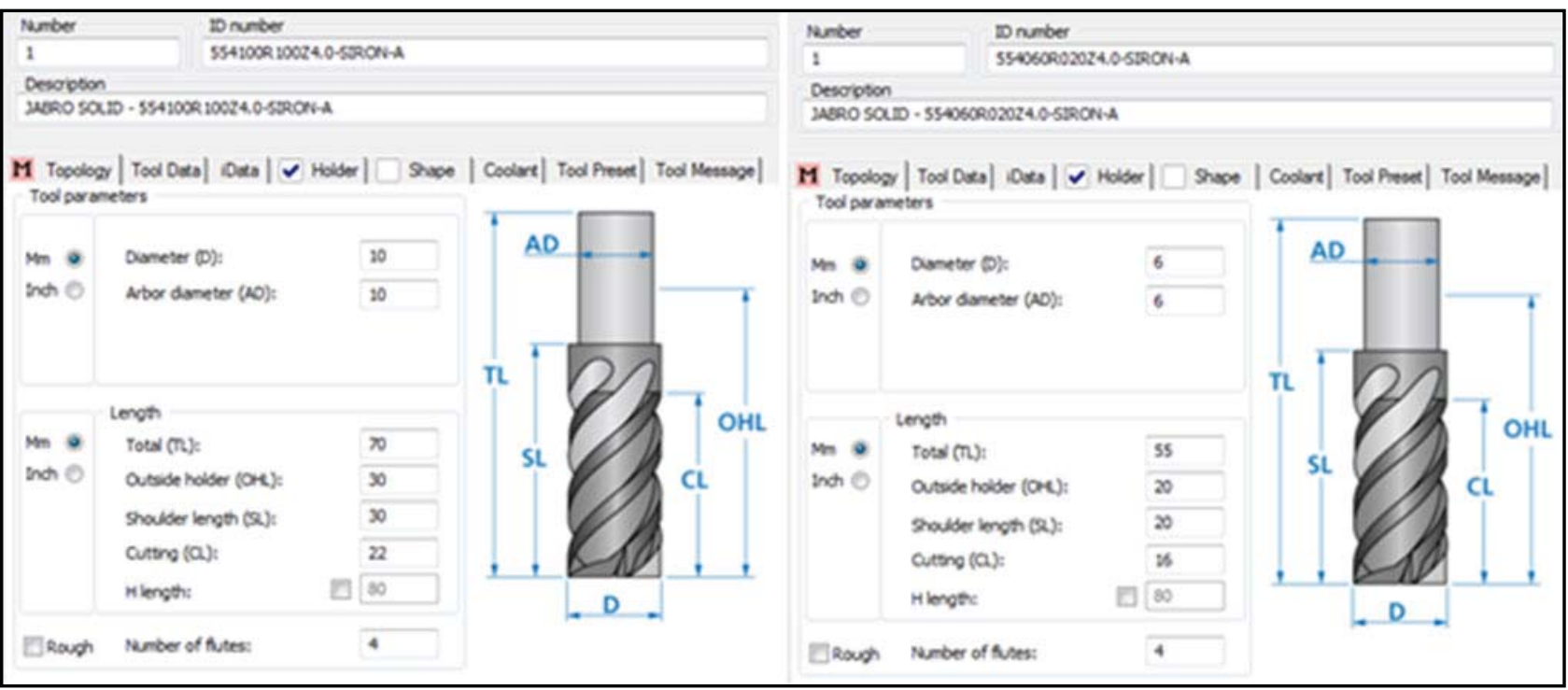

Figure 8: Geometric parameters of End Mill tool used - SECO-JABRO SOLID

For the machining of this particular example of heat exchanger we used milling machine Mazak $\mathrm{FH} 4800$, with the following properties, Table 2:

Table 2: Basic data of Milling machine - Mazak FH480

\begin{tabular}{|l|c|}
\hline Max spindle speed [rpm] & $\mathbf{2 5 0 0 0}$ \\
\hline Max cutting feed [mm/min] & 15000 \\
\hline Power [kW] & 40 \\
\hline Effeciency [\%] & 90 \\
\hline
\end{tabular}

\section{PREPARATION OF EXECUTIVE GCODE FILE FOR PROGRAMING OF CNC MACHINES}

Besides enhancing productivity in machining, imachining technology simplifies the process of defining technological operations and reduces the number of tools required for the production of parts because it enables machining with lower tool diameter. This leads to shorter preparation period for executive $\mathrm{g}$ code file for programing of $\mathrm{CNC}$ machines. The user is required to choose the machine which would be used in the machining process and workpiecematerial from technological imachining base and the most suitable Tool for the part in specific, Figure 9.

\begin{tabular}{l} 
Machining Data \\
Machine Database: \\
MH4800-Mars \\
Material Database: \\
TiAl6V4 \\
Machining Level: \\
6 \\
\hline $\begin{array}{c}\text { Edit iMachining } \\
\text { Database }\end{array}$ \\
\hline
\end{tabular}

Figure 9: Selected machine, workpiece material

Software with the use of suitable automatisms scans and compares the volume of the target part and the stock part, and defines the optimum tool path. When calculating the tool path and cuttingconditions, algorithm takes into consideration the properties of machine and workpiecematerial, as well as all tool parameters. Based on the machine limitation andcapability, tool diameter and number of tool cutting edges the cutting speed and cutting feed are being calculated for a given workpiecematerial, Figure 10. 


\begin{tabular}{|c|c|c|c|c|c|}
\hline \multicolumn{3}{|l|}{ Feed } & \multicolumn{3}{|l|}{ Spin } \\
\hline (2) $\mathrm{F}(\mathrm{mm} / \mathrm{min})$ & \multicolumn{2}{|c|}{ FZ (mm/tooth) } & (2) $S$ (rpm) & \multicolumn{2}{|c|}{$\mathrm{V}(\mathrm{m} / \mathrm{min})$} \\
\hline Feed XY: & 且 & 4698 & Spin rate: & 8 & 6468 \\
\hline Feed XY max: & $\square$ & 2877 & Spin finish: & $\square$ & 3757 \\
\hline Feed finish: & $\square$ & 1050 & Spin helical: & $\square$ & 4851 \\
\hline Feed Z: & $\square$ & 11990 & Spin direction & & \\
\hline Feed helical: & $\square$ & 3524 & ( ) $\mathrm{CW}$ & OC & \\
\hline Feed reposition: & 回 & 11990 & & & \\
\hline
\end{tabular}

Figure 10: Optimum calculated cutting speed and cutting feed

Software automatically calculate the maximum cutting depth based on the length of the tool cutting edge and workpiece geometry, which is later adjusted to final product geometry, by machining, first, the deepest zones, and then tool is lift- ed higher in accordance with demanded surface roughness(Scallop). This is an inverse process (Step-Up) of geometry scanning procedure considering the previous CAM high speed machining (HSM) processes, Figure 11.
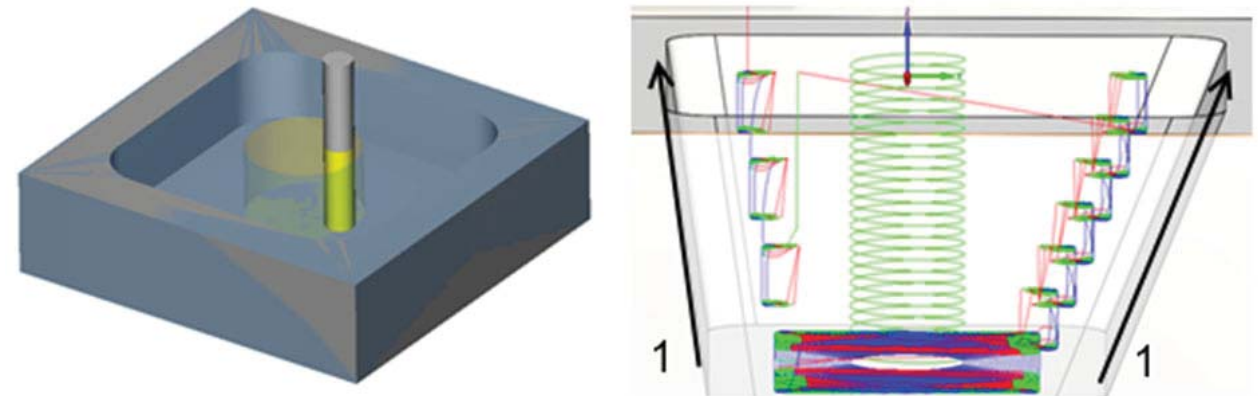

Figure 11: Geometry scanning procedure by imachining technology

The user has the freedom to define machining aggressiveness depending on the clamping conditions and workpiece stability, cooling possibility and tool condition, during which this technology synchronizes all cutting condition in every tool path point, Figure 12. This enables fast and simple adjustment, as well as fine tuning of the tool path to the current cutting conditions and processing new executive $g$ code files for programing of CNC machines.

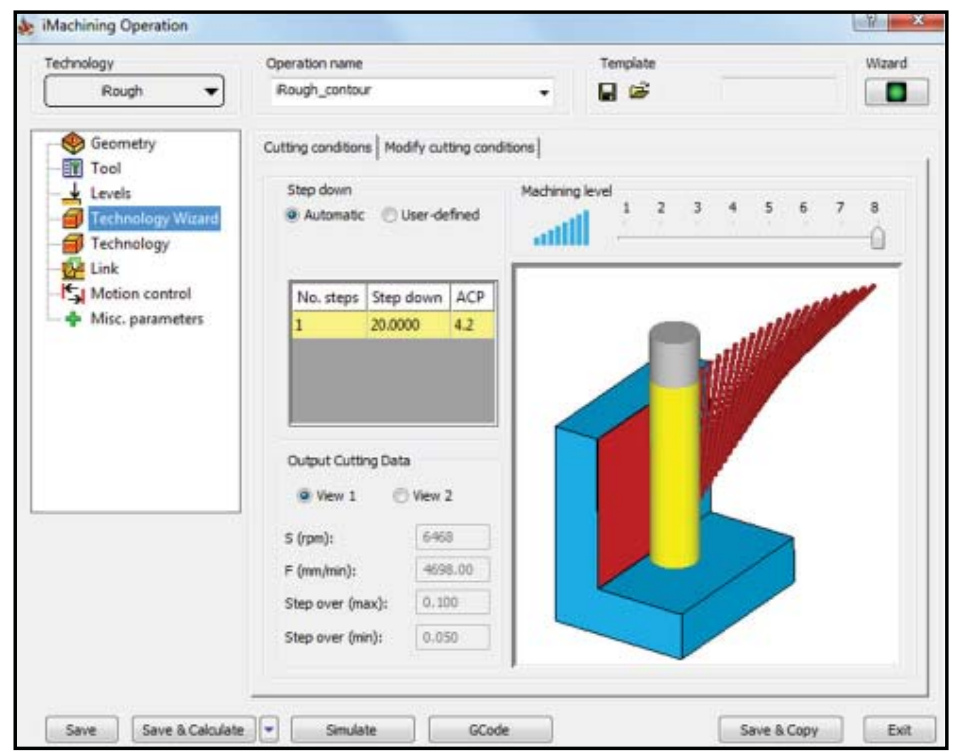

Figure 12: Dialog window for selection - defining machining aggression degree 
During this technology testing, we have done machining with several different setups and we have come tofollowing conclusions:

Number of the cutting edges:first of all, the cutting tool been used by three with different number of the cutting edges and of the SECOJABRO SOLID series. Apparently, we have used the tool with two, three and four cutting edges. Two cutting edges made good machining but the machining time was too big. Machining with four cutting edges caused high cutting speed, and this is not well demonstrated in the processing of this material because of high temperature in machining zone. We have concluded the three cutting edges of the tool is the best solution for this case.

Number of axial contact points(ACP):We have concluded that the number of contact points of tool spiral and workpiece directly affects the increased vibration occurrence. The integrated algorithm, based on the diameter, number of tool cutting edges and tool helix angle, calculates the number of contact points and warns the user about the possibility of vibrations occurring. This way user could choose a tool of different geometric properties or change cutting depth in order to reduce vibration during machining, Figure 13.

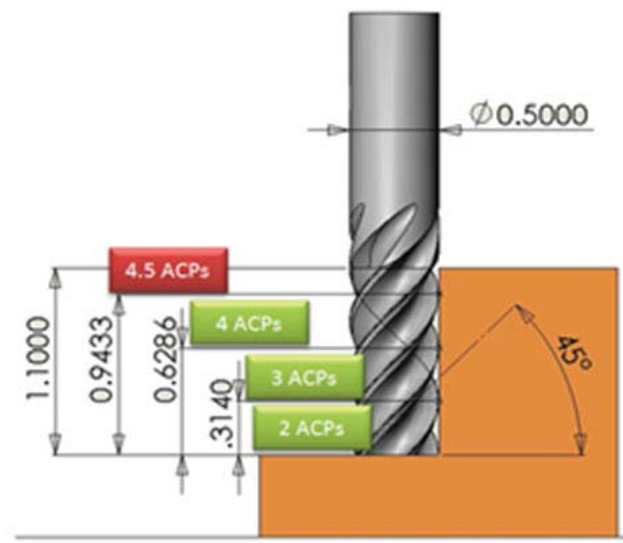

Figure 13: Number of ACP - axial contact points

Machining aggressiveness (machining level): The maximal possible machining level depends of many factor, including: characteristics of the tool and workpiece, capabilities of the machine and the level of clamping and coolant lubricant. For first test we select machining level 4 , and this was demonstrated as very well. We have made several tests and conclude that the best machining level for this case is level 8.In this machining level cutting condition was:

$\mathrm{S}=6468[\mathrm{rpm}]$

Feed $_{\min }=2877 \div 4698[\mathrm{~mm} / \mathrm{min}]$

Side step $=0.05 \div 0.1[\mathrm{~mm}]$

\section{TOOL PATH IN IMACHINING TECHNOLOGY}

Imachining technology is unique in its tool path shape in which are achieved. Integrated algorithm adjusts the tool path to workpiece geometry and create spiral tool path with changeable Side step and separates islands if it is necessary, Figure 14:

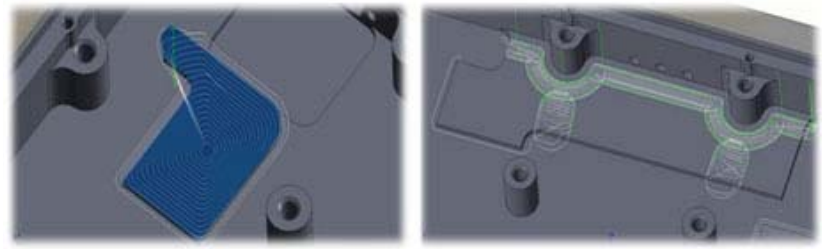

Figure 14: Example tool movement with spiral tool path, small number of elevation of the tool and island identification

\section{IMACHINING TECHNOLOGY DEVELOPMENT TENDENCIES}

SolidCAMCompany is working on developing advanced models of this technology for complete automation of machining preparation process, when the user would be able to choose one of three possibilities given to him while creating tool path:

Minimum machining cycle time - this option might be used when a certain part is machined with cheaper tool on high performance machine, due to short delivery deadlines,

Longest tool working life - users would be able to decide for this option in order to keep the 
current tool, due to the tool storeroom shortage, up to the date of the delivery of the final part or product,

Lowest cost - algorithm would find the right balance between machining time and tool working life by using data fromtechnological base on tool cost and machine working hours.

In collaboration with cutting tool manufacturers, ISCAR Company among others, new tool series are being developed with adjusted cutting part tool geometry and increased number cutting tool edges (6-12). These will farther increase productivity and Tool life.

\section{CONCLUSION}

Imachining technology represents unique and revolutionary machining technology on the market of CAM software; it enables manufacturing cost reduction and increases productivity among materials difficult for machining. Application of SolidCAMimachiningtechnology in machining of the mentioned heat exchanger we have managed to save $36 \%$ of machining time, when compared to standard HSM machining, Figure 15.

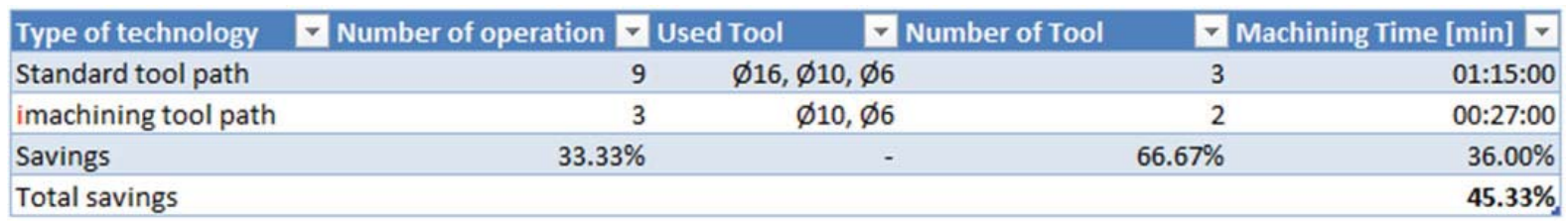

Figure 15: Comparative tables of achieved results in machining time by applying SolidCAMimachining technology and standard HSM machining

When machining of lighter materials time savings are smaller but not venial. This technology development enables companies dealing with machining services to accept tasks which they were unable to fulfill due inexperience and insufficient knowledge in the material machining area.

\section{List of symbols}

Cutting Speed V [m/min]

Spindle Speed S [rpm]

Cutting Feed $\mathrm{F}$ [mm/min]

Side step [mm]

Max spindle speed [rpm]

Max cutting feed [mm/min]

Power - power of the machine motor [kW]

Helical Angle - helix angle of the cutting edge of the tool defined by the tool manufacturer $\left[{ }^{\circ}\right]$

ACP - axial contact points of the tool cutting edge and the workpiece which depend of the cutting depth, diameter and number of cutting edges and tool helix angle

Efficiency - current condition of the machine [\%]

\section{REFERENCE}

1) David Pancoast (2013), SolidWorks, Concord, Massachusetts, USA, 2009.

2) Glišović, J., Demić, M., Miloradović, D. (2011): „Review of virtual reality applications for reducing time and cost of vehicle development cycle", Journal of Applied Engineering Science (Istraživanjaiprojektovanja za privredu), No. 3, Vol. 9, pp. 361-372

3) Ogrizovic M. (2008): Upravljanje CNC masinamaiz ProENGINEER-a Wildfire, Kompjuterbiblioteka, Beograd

4) Ogrizovic M. (2012): Programiranje CNC masina, Kompjuterbiblioteka, Beograd

5) SolidCAM Technical Support, 2013: SolidCAM_2013_FAQ_iMachining,SolidCAM Company

6) Stanisavljev, S., Ćoćkalo, D., Đorđević, D., Minovski, R. (2013): „The production cycle time in serial production: reduction of the duration in metal processing industry case", Journal of Applied Engineering Science (Ist raživanjaiprojektovanjazaprivredu), No. 3, Vol. 11, pp. 116-122

Paper sent to revision: 21.09.2013.

Paper ready for publication: 11.12.2013. 